\title{
Reproductive System Findings Baseline Flag
}

National Cancer Institute

\section{Source}

National Cancer Institute. Reproductive System Findings Baseline Flag. NCI Thesaurus.

Code C117651.

An indication or description that reproductive system findings data is a baseline value. 